\title{
Cathodic Recirculation System Using a Dual-ejector to Improve Oxygen Utilization of a Submarine Fuel Cell
}

\author{
Minjin Kim*, Young-Jun Sohn, and Won-Yong Lee \\ Fuel Cell Research Center, Korea Institute of Energy Research, 71-2, Jang-dong, Yuseong-gu, Daejeon, 305-343
}

(Received July 16, 2010 : Accepted July 29, 2010)

\begin{abstract}
In terms of the system efficiency, it is very useful to apply the ejector into the fuel recirculation system of a fuel cell system since the ejector needs no parasitic power to operate. Since the conventional automotive fuel cell use hydrogen and air as their fuel, the only hydrogen is needed to be recirculated for the better fuel efficiency. On the other hand, the submarine fuel cell needs both hydrogen and oxygen recirculation systems because the submarine drives under the sea. In particular, the cathodic recirculation has to meet the tougher target since the oxygen based pressurized stack generally used in the submarine applications generates the significant amount of the water in the stack during the operation. Namely, the oxygen utilization has designed less than $50 \%$ in the whole operating range for the better exhausting of the generated waters. And thereby in terms of the oxygen utilization, the entrainment ratio of the ejector should be more than 1 within the whole operating range. However, the conventional ejector using a constant nozzle can not afford to satisfy the mentioned critical requirement. To overcome the problem, the dual-ejector and its control strategy are designed. The performance of the proposed dual-ejector is verified by the experiments based on the real operating conditions of the target submarine system. Furthermore, the proposed design method can be used for the other fuel recirculation system of a large-scale fuel cell system with the critical requirement of the fuel utilization.
\end{abstract}

Keywords : Fuel cell, Submarine, Cathodic Recirculation, Dual-ejector

\section{Introduction}

The fuel recirculation management is the one of the important issues of the fuel cell to improve the system efficiency. Compared to the power consuming equipments such as a pump and a blower conventionally applied to the oxygen recirculation system, the ejector is very helpful for its better efficiency, operation, and maintenance since the ejector needs no parasitic power and has very simple mechanical structure. Many research works have performed the ejector design for the refrigeration system, absorption system, and so on. ${ }^{1-4)}$ Rodatz et al. proposed the use of an ejector instead of a pump or a blower as an anodic recirculation system of a fuel cell system. ${ }^{5}$ However in case of the fuel cell system for large-scale systems like submarines, it is difficult that the ejector is applied into that fuel cell system. Be-

*E-mail: minjin@kier.re.kr cause the fuel cell with a large capacity is required for the submarine and the power supply range of the fuel cell is very wide and changeable while the acceptable operating range of the conventional ejector with constant nozzle is too narrow to cover the whole operation range. In other words, the conventional ejector shows good performance for recirculation only within the narrow operating range near its design value. To solve this problem, some studies have suggested the multistructural ejector such as variable nozzle ejector and hybrid recirculate system with additional equipment. ${ }^{6-9)}$ However, these approaches still have some practical limitations such as leak problem, mechanical complexity, the consumption of additional electricity power, and frequent equipment errors.

In this paper, the design methodology of the dual-ejector which consists of two constant nozzle ejectors and one on/off valve is proposed. The ejector manufactured according to the design values is verified by experimental 
test within the operating range for the submarine PEMFC. The performance of the proposed ejector is acceptable in overall operating range even its simple structure.

\section{Dual-ejector Development}

Fig. 1 shows the experimental entrainment ratio of the constant nozzle ejector with respect to the required fuel cell power. The entrainment ratio of an ejector is calculated by Eq. 1. The constant nozzle ejector is the single ejector designed and manipulated for the target submarine PEMFC. The entrainment ratio of the constant nozzle ejector shows the maximum performance at the designed fuel cell power however it is degraded by changing the fuel cell power. It is noted that the acceptable operation range of the constant nozzle ejector is too narrow to be applied into the fuel cell system with the large capacity like a submarine fuel cell. Thus the single constant nozzle ejector is not available to be applied to the submarine fuel cell system.

$$
\omega=\frac{F_{s}}{F_{p}}(1)
$$

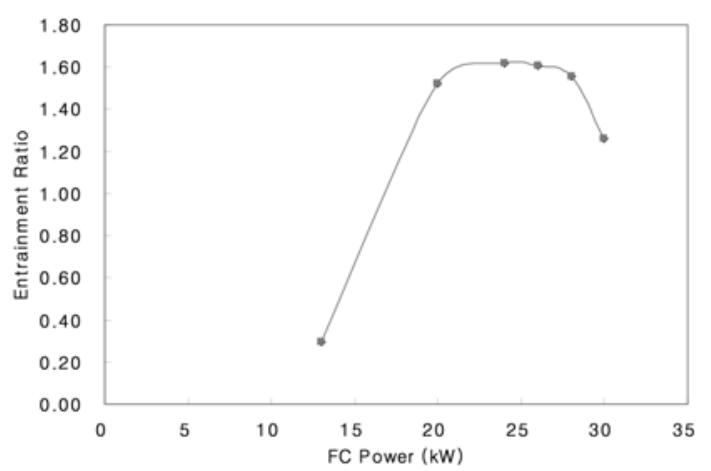

Fig. 1. Experimental entrainment ratio of the conventional ejector with the constant nozzle throat.
In this paper, the dual-ejector is proposed to solve this problem. The dual-ejector consists of the two single ejectors and one on/off valve as shown in Fig. 2. Each single ejector is designed to cover the half capacity of the fuel cell. At the high power range of the fuel cell, the primary flow according to the full power is divided from the fuel tank and is supplied to each single ejector. And then the unused oxygen is divided from the fuel cell stack and is recirculated by each ejector when the on/off valve is open. On the other hand, at the low power range of the fuel cell, the required primary flow is supplied to one single ejector and the unused oxygen is recirculated by the single ejector by being closed the on/off valve in front of the other single ejector. The proposed dual-ejector gives better performance as like the variable nozzle ejector without any leak problem by using two single ejectors. After all, the developed dual-ejector minimizes the parasitic power and the system complexity as well as maximizes the acceptable operation range for the submarine PEMFC system.

The steps to develop the dual-ejector are followings. At the first step, the single ejector is designed at $60 \%$ of its assigned capacity (the half capacity of the fuel cell). At the second step, the ejector manipulated based on the design results is tested its performance considering both the fuel utilization and the pressure drop at the fuel cell cathodic channel used to the submarine system. At the third step, two estimation models which represent the relationship between the entrainment ratio and the fuel cell power for the single and dual ejectors are built based on their experimental performance data. At the final step, the control procedure including the operation of the on/off valve is proposed using the performance estimation models of the ejectors. The followings show the detail development procedure at each step.

\section{$\underline{\text { Step 1: Design of Single Ejector }}$}

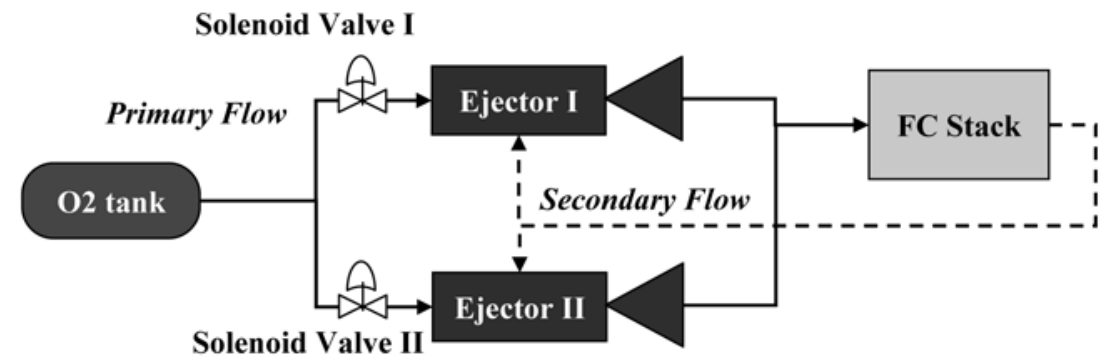

Fig. 2. Construction of the proposed dual-ejector. 
The performance of the ejector depends on the operating conditions of the PEMFC system. The operating conditions of the ejector are directly determined by the fuel cell system as followings; 1) the primary flow rate of the ejector is decided by the various load required by the submarine: 2) the exit pressure of ejector has to reach the inlet pressure of the PEMFC stack; 3) the suction pressure in the recirculation flow has to drop into the stack outlet pressure which decreases throughout the cathodic flow field; and 4) the temperatures of the primary and secondary flows are varied by the operating temperature of the stack outlet condenser. From the given ejector design conditions, the pressure, temperature, flow rate of the primary and secondary flows are determined. The design conditions of ejector from the target submarine PEMFC system are determined as shown in Table 1.

Based on the determined design conditions, the design values are calculated using the one-dimensional fundamental equations. Firstly, the ejector exit pressure is iteratively calculated by gradually updating the primary flow pressure until the calculated exit pressure is approximately equal to its required value. The optimal design value for the nozzle throat and mixing tube areas are also iteratively decided by updating the secondary flow Mach number until the relationship between the primary flow pressure and the ejector exit pressure is acceptable. The details including the equations and assumptions used to design the single ejector can be explained at. ${ }^{10}$

The recirculated flow of the PEMFC includes the water generated during the electric chemical reactions. In that case, the entrainment ratio is generally reduced since the molecular weight of the humidified oxygen is larger than the pure oxygen. To overcome the problem, it is necessary to increase both the driving force from the primary flow and the suction force of the secondary flow. The effect of the humidified oxygen is also considered at this

Table 1. Design Conditions of the Ejector for the Submarine PEMFC

\begin{tabular}{lcc}
\hline Name & Unit & Value \\
\hline Submarine Fuel Cell Maximum Power & $\mathrm{W}$ & 30000 \\
Primary Flow Pressure & $\mathrm{kPa}$ & $200 \sim 600$ \\
Primary Flow Temperature & $\mathrm{K}$ & 293 \\
Secondary Flow Pressure & $\mathrm{kPa}$ & 220 \\
Secondary Flow Temperature & $\mathrm{K}$ & 323 \\
Oxygen Stoichiometry & - & 2 \\
Total Oxygen Flow Rate & $\mathrm{SLPM}$ & 300 \\
Ejector Exit Pressure & $\mathrm{kPa}$ & 250 \\
\hline
\end{tabular}

design step with the properties of the humidified oxygen fuel like shown in. ${ }^{10)}$ The final designed diameters of nozzle throat and mixing tube are $1.2 \mathrm{~mm}$ and $3.3 \mathrm{~mm}$.

\section{Step 2: Single and Dual-ejector Performance Test}

The required power of the submarine PEMFC is from 5 to $30 \mathrm{~kW}$. Table 2 shows the experimental conditions with respect to the required power for the submarine PEMFC. The required oxygen flow rate and its theoretical and practical pressure drops are calculated according to various fuel cell powers. The theoretical pressure drop means the decreasing pressure through the only cathodic channel and is calculated by referring to. ${ }^{11)}$ On the other hand, the practical pressure drop means the totally decreasing pressure occurred at the condenser, lines, pressure transducer as well as the cathodic channel.

At each experimental condition, the entrainment ratio for the ejector is investigated. The results of the load change experiment for the single and dual ejectors are showed in the Fig. 3. For the single ejector, the entrainment ratio is from 0.56 to 1.56 at the practical pressure drop. For the dual-ejector, the entrainment ratio is from 0.30 to 1.26 at the practical pressure drop. The target stoichiometry of oxygen fuel is 2.0 and thereby the target

Table 2. Experimental Conditions of the Oxygen Flow Rate and Pressure Drop in Cathodic Channel by Changing the Required Power

\begin{tabular}{cccc}
\hline $\begin{array}{c}\text { Power } \\
(\mathrm{kW})\end{array}$ & $\begin{array}{c}\text { Oxygen Flow } \\
\text { Rate (SLPM) }\end{array}$ & $\begin{array}{c}\text { Theoretical Pressure } \\
\text { Drop in Cathodic } \\
\text { Channel (kPa) }\end{array}$ & $\begin{array}{c}\text { Practical Pressure } \\
\text { Drop in Cathodic } \\
\text { Channel (kPa) }\end{array}$ \\
\hline 10 & 100 & 1.9 & 8.6 \\
20 & 200 & 3.9 & 17.5 \\
30 & 300 & 5.8 & 26.1 \\
\hline
\end{tabular}

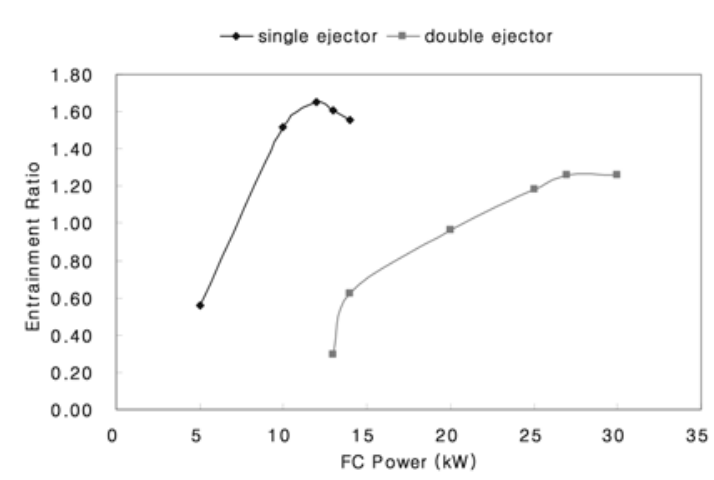

Fig. 3. Experimental entrainment ratio of the single ejector by changing the required fuel cell power. 
entrainment ratio of the dual-ejector is 1.0. As a result, the single ejector is acceptable between $6.7 \mathrm{~kW}$ to $15 \mathrm{~kW}$ and the dual-ejector is acceptable in the power range from $20 \mathrm{~kW}$ to $30 \mathrm{~kW}$. Shortly the designed ejector shows good performance during whole operation.

Step 3: Entrainment Estimation Models for the Single and Dual-ejectors

As shown in Fig. 4, the performance estimation models for the ejector entrainment ratio are fitted based on the quadratic equation. The least square method is used to build the models. Fig. 4 shows the experimental entrainment ratio of the single and dual ejectors with respect to the required fuel cell power and their estimation models. Eq. 2 and 3 are the estimation models of the single ejector and the dual-ejector. They have the high prediction accuracy of $99.91 \%$ and $99.05 \%$, respectively.

$$
\hat{\omega}_{s e}=-0.0208 P_{F C}^{2}+0.5058 P_{F C}-1.4500(2)
$$
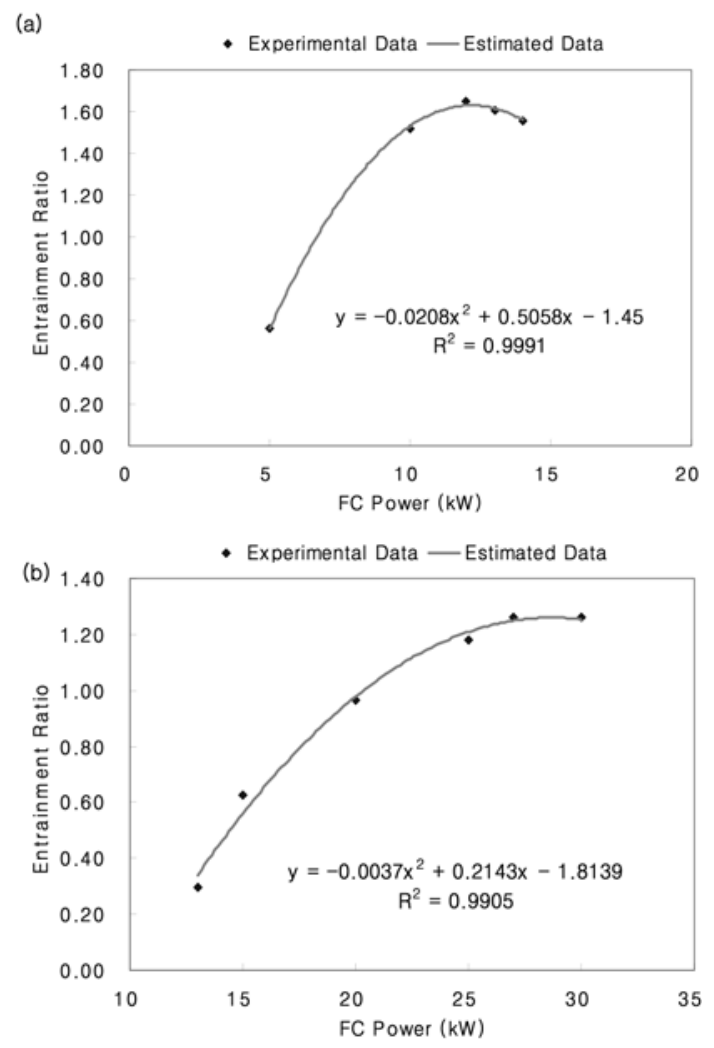

Fig. 4. Experimental entrainment ratio: (a) for the single ejector and (b) for the dual-ejector.

$$
\hat{\omega}_{d e}=-0.0037 P_{F C}^{2}+0.2143 P_{F C}-1.8139(3)
$$

Step 4: Control of the Dual-ejector

To control the dual-ejector, it is necessary to select better one among the single ejector mode and the dualejector mode according to the change of the required fuel cell power. Fig. 5 is the general control procedure for the multi-ejector. The symbol $i$ is one of the 1 and 2 when the target is the dual-ejector. The operating mode is decided by opening or being closed the on/off valve. The better operating mode is determined by comparing the measured and estimated entrainment ratios. The current entrainment ratio can be measured using flow rate sensors and the estimated entrainment ratio for the standby operating mode can be predicted from the performance model. The initial mode is the single ejector mode and then the operating mode is automatically changed by the control algorithm.

\section{Results and Discussion}

Fig. 6 shows the experimental entrainment ratio of the proposed dual-ejector with respect to the required fuel cell power. The available power range of the submarine PEMFC is from $5 \mathrm{~kW}$ to $30 \mathrm{~kW}$. In that range, the entrainment ratio changes from 0.8 to 1.58 considering with the practical cathodic pressure drop. Shortly, the developed dual-ejector is mostly acceptable in the overall operation range of the submarine PEMFC. The performance of the dual-ejector is little below the target

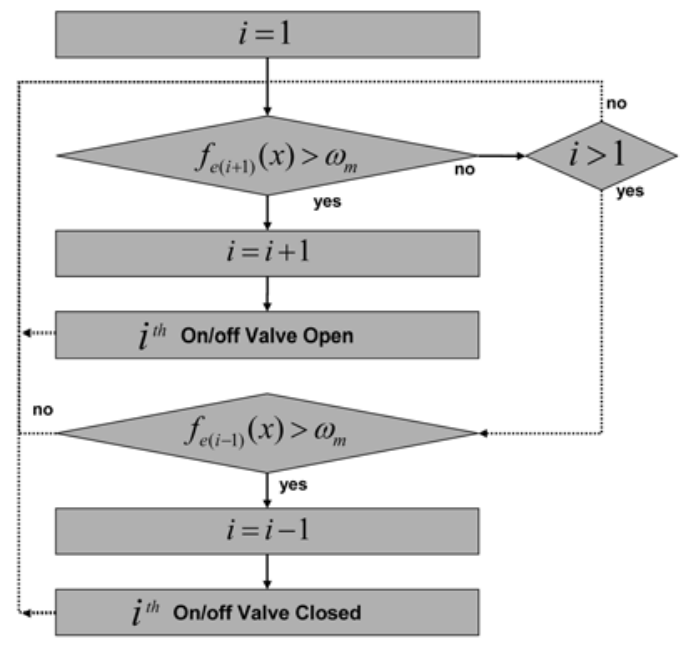

Fig. 5. Control procedure of the dual-ejector. 


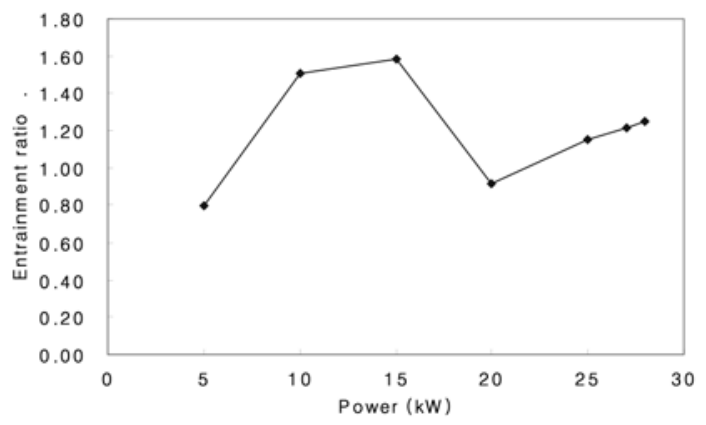

Fig. 6. Experimental entrainment ratio of the proposed dual-ejector with respect to the required fuel cell power.

entrainment ratio. However the difference is negligible to normally recirculate the oxygen. Consequently, the proposed ejector can be used to the oxygen recirculation system of the target submarine system without any supporting equipment.

\section{Conclusion}

The dual-ejector is proposed for the oxygen recirculation system of the submarine PEMFC system. The real ejector has been designed by the proposed methodology and the manipulated ejector has been verified its performance through the whole operations of the target system. The proposed ejector keeps its acceptable performance during its overall operating range without any additional equipment. In addition, the developed ejector allows not only the general advantages such as no parasitic power and better system efficiency but also the mechanical advantages such as the system simplicity, easy operation and maintenance, and no leak problem. The proposed design methodology is expected to be applied into many other large capacity automotive PEMFC applications which need to recirculate the unused oxygen and/or hydrogen.

\section{Acknowledgments}

This work was supported in part by Ministry of Knowledge Economy and by Ministry of Education, Science Technology.

\section{Nomenclature}

$P$ : power (W)

$F:$ flow rate (SLPM) $f:$ model based estimated entrainment ratio of ejector

$\omega$ : entrainment ratio of ejector

$\hat{\omega}$ : model based estimated entrainment ratio of ejector

Subscripts

$F C$ : fuel cell

de: dual-ejector

$e: \quad$ estimated value

$i$ : number of the ejectors in the multi-ejector

$m:$ measured value

$p: \quad$ primary flow of an ejector

$s: \quad$ secondary flow of an ejector

se : single ejector

sat : saturation

\section{References}

1. E. D. Rogdakis and G. K. Alexis, 'Investigation of ejector design at optimum operating conditioin' Energy Convers. Manage., 41, 1841 (2000).

2. S. K. Chou, P. R. Yang, and C. Yap, 'Maximum mass flow ration due to secondary flow choking in an ejector refrigeration system' Int. J. Refrig., 24, 486 (2001).

3. A. Levy, M. Jelinek, and I. Bored, 'Numerical study on the design parameters of a jet ejector for absorption systems' Appl. Energy, 72, 467 (2002).

4. R.Yapici and H. K. Ersoy, 'Performance characteristics of the ejector refrigeration system based on the constant area ejector flow model' Energy Convers. Manage., 46, 3117 (2005).

5. P. Rodatz, A. Tsukada, M. Mladek, and L. Guzzella, 'Efficiency improvements by pulsed hydrogen supply in PEM fuel cell systems' Proceedings of the 15the IFAC Triennial World Congress, IFAC, (2002).

6. F. Marsano, L. Magistri, and A. F. Massardo, 'Ejector performance influence on a solid oxide fuel cell anodic recirculation system' J. Power Source, 129, 216 (2004).

7. M. L. Ferrari, A. Traverso, L. Magistri, and A. F. Massardo, 'Influence of the anodic recirculation transient behavior on the SOFC hybrid system performance' J. Power Source, 149, 22 (2005).

8. A. Y. Karnik, 'Modeling and control of an ejector based anode recirculation system for fuel cells' Proceedings of FUELCELL2005, Ypsilanti, Michigan, (2005).

9. B. J. Huang, J. M. Chang, C. P. Wang, and V. A. Petrenko, 'A 1-D analysis of ejector performance' Int. J. Refrigeration, 22, 354 (1999).

10. M. Kim, Y. -J. Sohn, C. -W. Cho, W. -Y. Lee, and C. -S. Kim, 'Customized design for the ejector to recirculation a humidified hydrogen fuel in a submarine PEMFC' $J$. Power Source, 176, 529 (2008).

11. R. O'hayre, J.-W. Cha, W. Colella, and F. B. Prinz, "Fuel Cell Fundamentals", 182, John Wiley \& Sons, New York (2009). 